\title{
Genetic Structure, Transmission, Clinical Characteristics, Diagnosis, Treatment and Prevention of Coronavirus Disease 2019 (COVID-19): A
}

\section{Review}

\author{
Rawaa S. Al-Mayyahi*,1 and Wa'il A. Godaymi Al-Tumah**
}

*Department of Clinical Laboratory Science, College of Pharmacy, University of Basrah, Basrah, Iraq. ** Department of Physics, College of Science, University of Basrah, Basrah, Iraq.

\section{Abstract}

The novel severe acute respiratory syndrome coronavirus 2 (SARS-CoV-2) caused a pandemic of coronavirus disease 2019 (COVID-19) which represents a global public health crisis. Based on recent published studies, this review discusses current evidence related to the transmission, clinical characteristics, diagnosis, management and prevention of COVID-19. It is hoped that this review article will provide a benefit for the public to well understand and deal with this new virus, and give a reference for future researches.

Keywords: Coronavirus, COVID-19, SARS-CoV-2, Pneumonia, Respiratory infection.

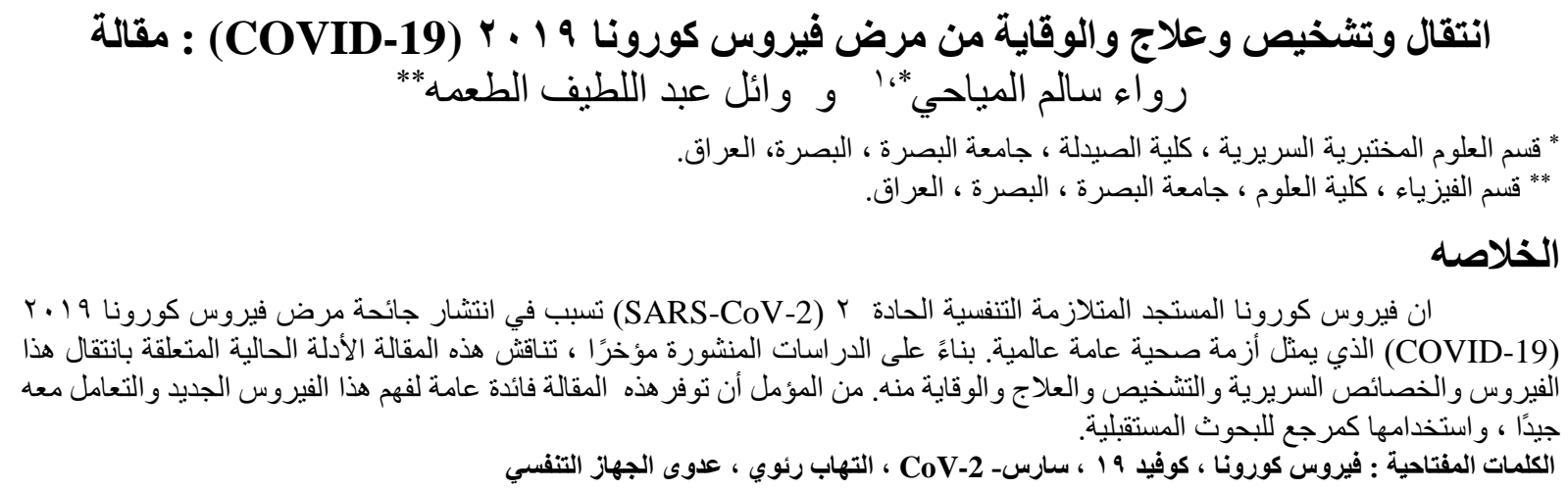

\section{Introduction}

Since December 2019, a series of unexplainable pneumonia cases were identified in Wuhan a central city in China ${ }^{(1-4)}$. By January 2020 , the results of deep sequencing data analysis from infected patient's samples, confirmed that a novel coronavirus named severe acute respiratory syndrome-related coronavirus 2 (SARS- CoV-2) is the causative agent for that observed mystery pneumonia $^{(5)}$. On February, 2020, the World Health Organization (WHO) named the disease caused by the SARS-CoV-2 as Coronavirus Disease-2019 (COVID-19) and by March, 2020, the WHO announced the outbreak of COVID-19 as a pandemic with confirmed cases in 114 countries. The number of infected patients exceeds 118,000 , and the death toll exceeds $4000^{(6)}$. On April the $10^{\text {th }}$, 2020, there have been more than 1,500,000 reported cases and about 93,000 deaths in more than 130 countries ${ }^{(7)}$. As of September 27, 2020, SARS-CoV2 has affected over 32.7 million reported cases and 991, 000 confirmed deaths ${ }^{(8)}$.

Interestingly, the rate of new COVID-19 cases has continued to increase and the rate of deaths has remained relatively stable. In October the $19^{\text {th }}$, more 42 million cases and 1.1 million deaths have been recorded around the world (Figure 1) ${ }^{(9)}$. The new type of coronavirus belongs to a large class of viruses called $\beta$-coronavirus. SARS-CoV-2 is similar to severe acute respiratory syndrome coronavirus (SARS-CoV) that caused the SARS$\mathrm{CoV}$ outbreak in 2002 and Middle East respiratory syndrome coronavirus (MERS-CoV) that caused the MERS-CoV outbreak in $2012^{(10-13)}$. However, a novel coronavirus has different potential natural, intermediate and final hosts. These results in major problems for the prevention and management of viral infection. Moreover, the new virus has high transmissibility and infectivity, and a low mortality rate compared with SARS-CoV and MERS-CoV (14). Here, in this review we would like to display the genetic structure, route of transmission, diagnosis, clinical characteristics, source of infection and to discuss the foundational knowledge on the therapies that have been suggested for the treatment of COVID-19. It is hoped that this review will provide researchers with an updated understanding of COVID-19 and also to help follow-up research, prevention and treatment.

${ }^{1}$ Corresponding author E-mail: rawaa.salim@uobasrah.edu.iq

Received: 11/11/2020

Accepted:13/2/2020

Iraqi Journal of Pharmaceutical Science 


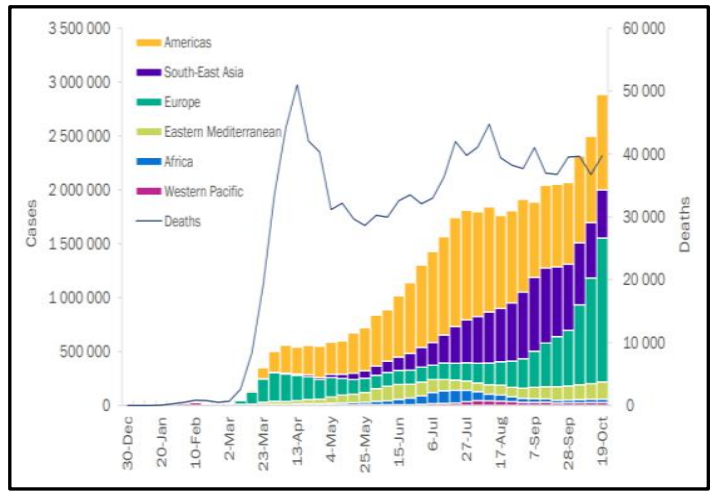

Figure 1. Number of COVID-19 cases reported weekly by WHO Region and global deaths (data as reported at on 19 October 2020) ${ }^{(9)}$.

\section{Genetic structure and pathogenic mechanism of SARS-CoV-2 \\ Coronaviruses are single-stranded} ribonucleic acid viruses with a diameter of 80-120 $\mathrm{nm}$. These viruses are found in humans and vertebrates, such as dogs, cats, chicken, cattle, pigs, and birds. Coronavirus can infect the respiratory, intestinal, and central nervous systems in humans and other mammals ${ }^{(15,16)}$. The genome sequence analysis showed that SARS-CoV-2 belongs to $\beta$ coronavirus family and it is similar to SARS-like bat coronaviruses, this reveals that SARS-CoV-2 might originate from bats ${ }^{(14)}$. Interestingly, several studies have investigated that SARS-CoV-2 uses angiotensin-converting enzyme 2 (ACE2) as an entry receptor ${ }^{(17-19)}$. Most of coronaviruses members use $\mathrm{S}$ proteins on their surface to recognize their corresponding receptors on host cells and gain entry into target cells and then cause infections (Figure 2). The experimental results showed that SARS-CoV-2 binds to ACE2 with 10- to 20- fold higher affinity than SARS-CoV ${ }^{(20,21)}$. However, the exact mechanism by which COVID 19 cause infection in humans through binding of S-protein to ACE2, a high human-to-human transmission rate, fast mutation and recombination and how SARSCoV-2 damage organs remain unclear, and therefore many studies are required. The current findings elucidate the rapid transmission ability of COVID19 in humans compared with SARS-CoV, and the greater number of confirmed cases of SARS-CoV-2 compared with SARS-CoV disease. Considering binding of SARS-CoV-2 with higher affinity with ACE2 and soluble ACE2 may be a possible candidate for the management of COVID-19 ${ }^{(22)}$.

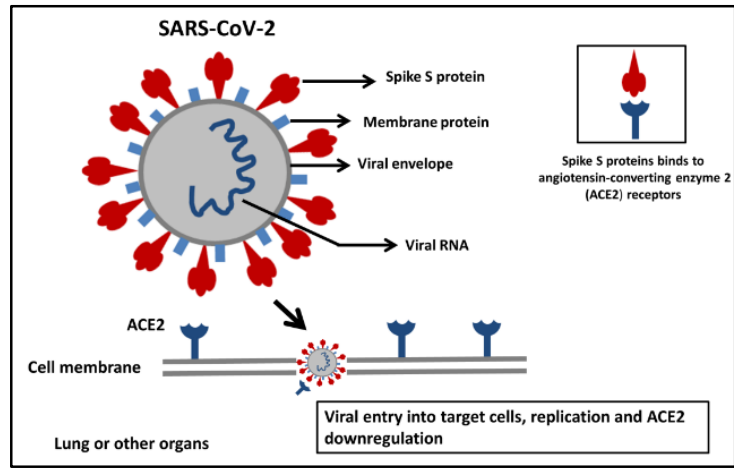

Figure 2. Viral entry mechanism of SARS-CoV-2 into the host cells.

\section{Transmission of SARS-CoV-2}

The natural hosts of SARS-CoV-2 are bats while the intermediate hosts are pangolins and snakes ${ }^{(23,24)}$. Virologic researchers found that SARS-CoV-2 is $96 \%$ similar to the whole-genome level of a bat coronavirus gene sequencing analysis (25). Recently, it is considered that the essential source of SARS-CoV-2 infection is infected persons. Epidemiologic results propose that droplets and close contact to patients with COVID-19 are the most common mode of transmission. Virologic studies suggest that SARS-CoV-2 is mainly transmitted from symptomatic people through coughing or sneezing. Further, recent studies revealed that SARS-CoV-2 found in samples of stool, gastrointestinal tract, saliva and urine these cause an infection risk in sewage networks, sanitary settings, wastewater treatment plants, and the wider environment such as rivers and lakes ${ }^{(26,27)}$. Short exposures to asymptomatic contacts are less likely to cause transmission ${ }^{(27)}$. Aerosols (tiny droplets that remain suspended in the air) are another possible source of COVID-19 infection in humans. Also, contaminated surfaces are another possible mode of transmission ${ }^{(28,29)}$. A case series of nine infected pregnant mother showed that there is a possibility of vertical transmission in the third trimester ${ }^{(30)}$. In most case series, the pregnant women infection with COVID-19 appeared in the third trimester of pregnancy and there were no maternal deaths and a favourable clinical course in the infants ${ }^{(30,31)}$. However, researches on pregnant infected with COVID-19 are insufficient; more studies are needed to verify the vertical transmission of SARS-CoV-2 from mother to neonates. The debate remains regarding SARS-CoV-2 transmissibility by indirect contact from inanimate surfaces. Studies have shown higher levels of the virus on impermeable surfaces, such as plastic, stainless steel compared with permeable surfaces, such as cardboard ${ }^{(32)}$. The previous studies have been shown that the coronavirus including the COVID-19 can remain viable on different surfaces for a prolonged time under controlled laboratory 
conditions ${ }^{(33)}$. The epidemiological studies investigate that elderly people are most vulnerable to COVID-19 (median age at death 75 years) ${ }^{(34)}$. Interestingly, the average age of hospitalized infected persons was 47 to 73 years, more men were admitted than women about (60\% male) in most groups ${ }^{(35)}$. Approximately $2 \%$ to $5 \%$ of infected patients with COVID-19 are younger than 18 years, with a median age of 11 years. A study of 1099 infected persons with COVID-19 showed that the median incubation time was three days (range 0-24 days), and the median period from symptom start to death was 14 days ${ }^{(34,36)}$. Also, in a study of 52 critically ill individuals with COVID-19 who were admitted to intensive care units, the mean age was 59.7 years, and the death rate was $61.5 \%$ by 28 days (37). Based on current evidence and clinical experience, it was found that the death rate for those over 80 years is 5 times higher than the global average. Eight out of 10 deaths reported in the United States were in adults over 65 years of age ${ }^{(38)}$. Also, it was reported that the percentage of death was increasing with age in United States (Figure 3) (39). Importantly, COVID-19 may be asymptomatic or it may cause different symptoms that include fever, myalgia, with diarrhea, respiratory distress and life-threatening sepsis (40,41). Interestingly, virologic studies investigate that SARS-CoV-2 can be transmitted by asymptomatic, presymptomatic, and symptomatic carriers ${ }^{(42)}$.

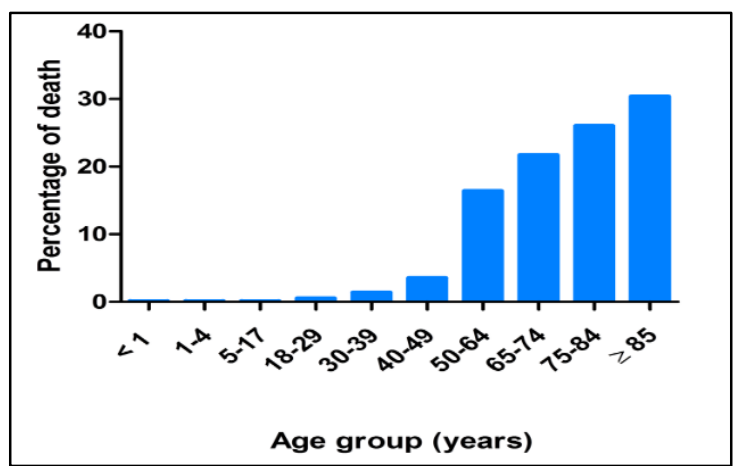

Figure 3. Percentage of death due to the coronavirus (COVID-19) in United States, May 1-August 31, 2020 increase with age ${ }^{(39)}$.

\section{Clinical characteristics of SARS-CoV-2}

The mean incubation period of SARSCoV-2 infection was (2-7) days; this is similar to the median incubation period of SARS-CoV which was (2-10) days ${ }^{(36,43,44)}$. Around $97.5 \%$ of infected persons who develop symptoms and signs will do so in 11.5 days of infection. The median time from symptom beginning to hospital admission is (3-9) days ${ }^{(44,45)}$. The most common symptoms in hospitalized individuals are fever $(90 \%$ of infected persons), dry cough (60\%-86\%), shortness of breath $(53 \%-80 \%)$, fatigue $(38 \%)$, vomiting or diarrhea $(15 \%-39 \%)$, and myalgia $(15 \%-44 \%)^{(5,46,47)}$. For most infected persons with COVID-19, $64 \%$ to $80 \%$ had olfactory and/or gustatory dysfunctions ${ }^{(48,49)}$. Furthermore, severe cases are susceptible to different complications, such as acute respiratory distress syndrome, coronary heart disease, hypertension, diabetes, cancer and other sever outcomes ${ }^{(50-53)}$. Also, it was observed that SARSCoV-2 can spread to other tissues organs and cause damage to kidney, liver, brain and ocular tissues (Figure 4) ${ }^{(54,55)}$. SARS-CoV-2 infection may be mild in children with a general case fatality rate less than $1 \%$. The relationship between children and the infection of COVID is unclear. The likely reasons may belong to their less robust immune responses and their lower rates of exposure to COVID-19. Despite most children cases are mild, about $(<7 \%)$ of cases develop severe symptoms and need mechanical ventilation and therefore admitted to the hospital ${ }^{(42)}$.

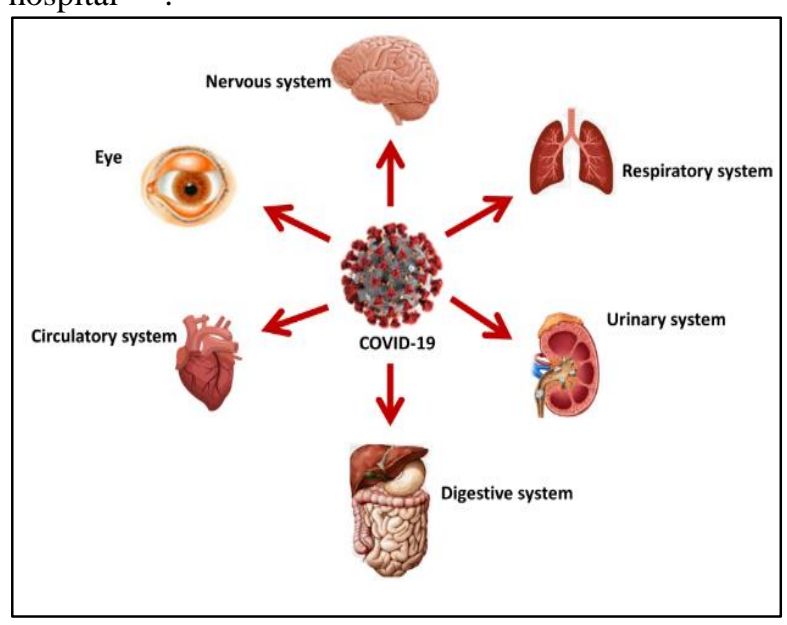

Figure 4. Schematic figure displaying the potential complications of SARS-CoV-2 impacting organ systems.

\section{Diagnosis of SARS-CoV-2}

In general, the diagnosis of SARS-CoV-2 is made by using polymerase chain reaction testing. However, SARS-CoV-2 nucleic acid testing has low sensitivity and high specificity; therefore, falsenegative test results may occur. There are several factors contributing to false-negative test results such as specimen source, adequacy of the specimen collection method and time from exposure. It was observed that lower respiratory samples are more sensitive than upper respiratory samples. A research group in China collected 1070 specimens from 205 infected persons with SARS-CoV-2, they were observed that $(93 \%)$ of positive rates of SARS-CoV2 PCR testing was in bronchoalveolar lavage fluid specimens, (72\%) was in sputum, (63\%) was in nasal swabs, and $(32 \%)$ was in pharyngeal swabs. Moreover, COVID-19 can also be found in feces, but not in urine ${ }^{(56)}$. Saliva is another source of SARS-CoV-2 which required less personal protective equipment, fewer swabs, and more 
validation $^{(57)}$. So, nasal swabs, laboratory, clinical and chest computed tomography (CT) scan can be also used in order to get a presumptive diagnosis ${ }^{(14,58)}$. Serological testing could help in the diagnosis of SARS-CoV-2 infection and also in the responses to novel vaccines. However, not all antibodies created in response to infection are neutralizing. Therefore, the presence of antibodies may not produce immunity ${ }^{(59,60)}$. A previous study succeeded to develop a rapid test (1 h) SARS- CoV2 detection using SHERLOCK technology (specific high-sensitivity enzymatic reporter unlocking) ${ }^{(61)}$. Also, a scientist group at Peking University suggested developing a new method for rapid construction of the transcriptome sequencing library of SHERRY which is useful for rapid sequencing of COVID-19. The transcriptome profiling by RNA sequencing (RNA-seq) is widely used to characterize cellular status. However, this method relies on second-strand complementary DNA (cDNA) synthesis to create initial material for library preparation ${ }^{(62)}$.

\section{Treatment of SARS-CoV-2}

There are different classes of drugs being assessed and developed for the treatment of COVID19. Antiviral drugs have been reported as a promising treatment of a broad array of RNA viruses. For example, remdesivir was initially developed for the management of Ebola hemorrhagic fever. In vitro and in vivo studies suggest its activity against filoviridae, paramyxoviridae and coronaviridae such as MERSCoV, SARS-CoV, and SARS-CoV-2 (5,63,64). Holshue et al. found that remdesivir attained good results against SARS-CoV-2 ${ }^{(65)}$. An in vitro study has shown the effectiveness of remdesivir in the control of COVID-19 ${ }^{(66)}$. Although a large number of clinical trials have been performed, the efficacy of remdesivir remains uncertain. Chloroquine and hydroxychloroquine have antiviral and immunomodulatory activities, they were clinically used against malaria and several viruses such as human immunodeficiency virus type 1 hepatitis B virus and herpes simplex virus type 1 . Chloroquine and hydroxychloroquine seam to prevent viral entry into cells and endocytosis of virus in vitro and may possess immunomodulatory effects in vivo ${ }^{(67,68)}$. Two previous studies among patients hospitalized for COVID-19 showed no effect of hydroxychloroquine on the risk of intubation or mortality ${ }^{(69,70)}$. One of these two previous cohort studies compared in-hospital mortality between 735 patients treated with hydroxychloroquine and azithromycin, 271 patients treated with hydroxychloroquine alone, 211 patients treated with azithromycin alone, and 221 patients without drugs. They found that there were no differences among the groups ${ }^{(69)}$. However, both compounds may cause rare and serious adverse effects, most notably QT prolongation, hypoglycemia, neuropsychiatric effects, and retinopathy ${ }^{(69,71,72)}$. The safety of chloroquine and hydroxychloroquine use during pregnancy was investigated ${ }^{(11)}$. A review of 588 patients treated with chloroquine or hydroxychloroquine in pregnancy observed no overt child ocular toxicity ${ }^{(73)}$. Clinical trials still ongoing and must give more guidance. Most antiviral agents that were previously used in SARS-CoV and MERS-CoV treatment are potential candidates to treat SARS-CoV-2. Lopinavir-ritonavir is a protease inhibitor developed for the treatment of human immunodeficiency virus (HIV) ${ }^{(74)}$. Although lopinavir/ritonavir disrupts viral replication in vitro, a randomized, controlled, open-label trial of 199 hospitalized infected persons with severe COVID19 shows no benefit when compared with standard care ${ }^{(75)}$. Ribavirin is RNA-dependent RNA polymerase inhibitors and uses against other novel coronaviruses. Therefore, it is a candidate for the treatment of SARS-CoV-2 ${ }^{(76)}$. However, its activity against SARS- CoV in vitro was limited, needed high dose and combination therapy in order to inhibit viral replication. Previous studies showed that patients received either intravenous or enteral administration while inhaled administration shows no benefit over enteral or intravenous administration $(77,78)$. It was demonstrated that the high doses of ribavirin used in the SARS-CoV trials caused haemolytic anaemia in more than $60 \%$ of patients ${ }^{(78)}$. The inconclusive efficacy results with ribavirin for other novel coronaviruses and its substantial toxicity propose that it has limited efficacy for COVID-19 treatment. However, its clinical efficacy may be improved with combination therapy. Ribavirin is also a known teratogen and contraindicated in pregnancy ${ }^{(79)}$. SARS-CoV infections induced a disproportionate immune response. Therefore, enhancing the body's immunity is a possible candidate protocol for treatment of individuals with COVID-19. Interferon can induce both innate and adaptive immune responses resulting in inhibition of viral infection ${ }^{(11,80)}$. Corticosteroids have potent anti-inflammatory and immunomodulatory properties therefore; they are used to suppress lung inflammation, particularly in the advanced stages of the disease ${ }^{(81)}$. Low doses of corticosteroids caused downregulation of pro-inflammatory cytokine transcription resulting in preventing extended cytokine responses and increasing the resolution of pulmonary and systemic inflammation in pneumonia. Moreover, corticosteroids can promote the dysregulated immune responses caused by sepsis (a potential complication of SARS-CoV-2) and may raise blood pressure in hypotensive patients ${ }^{(82-84)}$. However, corticosteroids reduced viral clearance from the respiratory tract and blood and provoke viral replication. Russell et al argued that the benefit of corticosteroids was greatest in patients with bacterial rather than viral infections ${ }^{(85)}$. Previous 
studies have reported that there was no survival benefit (and possibility for harm) among patients with SARS, MERS-CoV, and influenza receiving corticosteroids. However, preliminary results from the Randomized Evaluation of COVID-19 Therapy (RECOVERY) trial, which showed that dexamethasone reduced mortality across SARSCoV-2 patients with severe respiratory complications. The mortality was reduced by onethird in 2104 patients with COVID-19 receiving low doses of dexamethasone (6 mg daily, orally or intravenously) for up to 10 days and by one-fifth in patients taking oxygen only. The benefit was higher in patients who needed mechanical ventilation and in patients with symptoms for more than 7 days $(81,86)$. Furthermore, a previous cohort study in Wuhan, China, showed that methylprednisolone treatment reduced risk of mortality (hazard ratio, 0.38 [95\% CI, 0.20-0.72]) in 201 patients with COVID-19 and acute respiratory distress syndrome (ARDS) ${ }^{(87)}$. Convalescent plasma from infected persons who have recovered from viral infections with high specific antibodies against SARS-CoV-2 is selected as an alternative treatment for COVID19. It was first investigated during flu pandemic in 1918 and used to promote the survival rate of patients with SARS, MERS-CoV, H1N1 and Ebola, ${ }^{(88-91)}$. Indeed, convalescent plasma with neutralizing antibody was used in conjunction with continued methylprednisolone and antiviral treatment drugs to treat 5 critically ill SARS-CoV-2 patients with ARDS requiring mechanical ventilation. The findings showed improvement in clinical status among all participants ${ }^{(92)}$. In randomized clinical trial of 103 infected persons with severe COVID-19 observed there are no statistical differences in time to clinical improvement within 28 days across participants randomized to take plasma therapy vs standard treatment only $(51.9 \%$ vs $43.1 \%){ }^{(93)}$. However, consideration plasma-derived hyperimmune globulin and monoclonal antibodies against SARS-CoV-2 are another approaches deserve more consideration.

\section{Prevention and vaccine development of COVID- 19}

SARS-CoV-2 is a potentially preventable infection. The epidemiology of the new disease around the world reveals the clear relationship between the intensity of public health action and the control of transmission (27,94-96). The rates of transmission can be reduced using different infection control measures such as the use of protective equipment, home quarantine after infection, physical distancing, travel restrictions and restricting mass gatherings $(94,95,97)$. In addition, boosting the immune system is another way to prevent COVID-19. SARS-CoV-2 may cause acute respiratory distress syndrome and sepsis, therefore, a moderate amount of vitamin $\mathrm{C}$ may be a way to ameliorate inflammation and vascular injury in COVID-19 patients ${ }^{(98-100)}$. Moreover, the reduction in the amount of vitamin D and vitamin $\mathrm{E}$ in cattle may cause bovine coronavirus infection. Therefore, suitable amount of vitamin D and vitamin $\mathrm{E}$ may increase resistance to SARS-CoV-2 ${ }^{(101)}$. However, multiple interventions remain required until safe and potent treatments or vaccines become available. There are several approaches used to develop vaccines for SARS-CoV-2 such as nucleic acids (DNA or RNA), viral vectors, inactivated or live attenuated viruses and recombinant proteins or virus particles. However, the novel virus is an RNA virus, therefore, RNA-virus-related vaccines such as polio, measles, encephalitis B virus and influenza virus, represent the most promising alternatives. More than 120 vaccines are under development till now ${ }^{(102,103)}$. However, WHO expected that a minimum of 12 to 18 months would be needed before widespread vaccine deployment. Interestingly, on December the US Food and Drug Administration (FDA) endorsed Pfizer/BioNTech's and Moderna as safe and effective - COVID-19 vaccines. Both vaccines use messenger RNA (mRNA) technology, which includes instructions for human cells to make proteins that mimic part of the coronavirus. They target the crown-like spikes that found on the surface of the coronavirus ${ }^{(104)}$.

\section{Conclusions}

As of October 18, 2020, more than 40 million people worldwide had been infected with COVID-19. Therefore, COVID-19 represents the greatest global public health emergency after the pandemic of Spanish influenza in 1918. However, many features of infection, transmission, and treatment remain uncertain. Further basic and clinical studies are required in prevention and effective treatment of COVID-19.

\section{Abbreviations}

ACE2, angiotensin-converting enzyme 2; ARDS, acute respiratory distress syndrome; COVID-19, Coronavirus Disease-2019; HIV, human immunodeficiency virus; MERS-CoV, middle East respiratory syndrome coronavirus; SARS-CoV, severe acute respiratory syndrome coronavirus; SARS-CoV-2, severe acute respiratory syndrome-related coronavirus 2; WHO, World Health Organization.

\section{Funding}

This research did not receive any specific grant from funding agencies in the public, commercial, or not-for-profit sectors.

\section{Conflicts of Interest}

The authors report no conflicts of interest.

\section{References}

1. Zhao S, Musa SS, Lin Q, Ran J, Yang G, Wang $\mathrm{W}$, et al. Estimating the Unreported Number of 
Novel Coronavirus (2019-nCoV) Cases in China in the First Half of January 2020: A DataDriven Modelling Analysis of the Early Outbreak. J Clin Med. 2020;9(2):388.

2. Lu H, Stratton CW, Tang YW. Outbreak of pneumonia of unknown etiology in Wuhan, China: The mystery and the miracle. J Med Virol. 2020;92(4):401-2.

3. Twomey JD, Luo S, Dean AQ, Bozza WP, Nalli A, Zhang B. COVID-19 update: The race to therapeutic development Julianne. Drug Resist Updates. 2020;100733. Available from: https://doi.org/10.1016/j.drup.2020.100733

4. Addi RA, Benksim A, Amine M, Cherkaoui M. Asymptomatic COVID-19 Infection Management: The Key to Stop COVID-19. J Clin Exp Invest. 2020;11(3). Available from: www.jceionline.org

5. Huang C, Wang Y, Li X, Ren L, Zhao J, Hu Y, et al. Clinical features of patients infected with 2019 novel coronavirus in Wuhan, China. Lancet. 2020;395(10223):497-506.

6. Di Gennaro F, Pizzol D, Marotta C, Antunes M, Racalbuto V, Veronese N, et al. Coronavirus diseases (COVID-19) current status and future perspectives: A narrative review. Int J Environ Res Public Health. 2020;17(8).

7. World Health Organization. Situation Report81 April 10, 2020. 2020;(April). Available from: https :// www. who .int /docs /default source /coronaviruse / situation-reports / 20200410 -sitrep-81-covid-19. pdf? Sfvrsn $=$ ca96eb84_2

8. World Health Organization. Situation Report27 September, 2020 Coronavirus Disease (COVID-19). 2020;(September).

9. World Health Organization. COVID-19 Weekly Epidemiological Update. 2020;(October).

10. Barlow A, Landolf KM, Barlow B, Yeung SYA, Heavner JJ, Claassen CW, et al. Review of Emerging Pharmacotherapy for the Treatment of Coronavirus Disease 2019. Pharmacotherapy. 2020;40(5):416-37.

11. Sanders JM, Monogue ML, Jodlowski TZ, Cutrell JB. Pharmacologic Treatments for Coronavirus Disease 2019 (COVID-19): A Review. JAMA - J Am Med Assoc. 2020;323(18):1824-36.

12. Ashour HM, Elkhatib WF, Rahman MM, Elshabrawy HA. Insights into the recent 2019 novel coronavirus (Sars-coV-2) in light of past human coronavirus outbreaks. Pathogens. 2020;9(3):1-15.

13. Ullah MA, Araf Y, Sarkar B, Moin AT, Reshad RA HM. Pathogenesis, Diagnosis and Possible Therapeutic Options for COVID-19. J Clin Exp Invest. 2020;11(4).

14. Wang L, Wang Y, Ye D, Liu Q. Review of the 2019 novel coronavirus (SARS-CoV-2) based on current evidence. Int $\mathbf{J}$ Antimicrob Agents. 2020;55(January).

15. Cheng VCC, Lau SKP, Woo PCY, Yuen KY. Severe Acute Respiratory Syndrome Coronavirus as an Agent of Emerging and Reemerging Infection. 2007;20(4):660-94.

16. Chen Y, Liu Q, Guo D. Emerging coronaviruses : Genome structure, replication , and pathogenesis. J Med Virol. 2020 ;92 (4) :418-23.

17. Hoffmann $\mathrm{M}$, Kleine-Weber $\mathrm{H}$, Krüger $\mathrm{N}$, Müller M, Drosten C, Pöhlmann S. The novel coronavirus 2019 (2019-nCoV) uses the SARScoronavirus receptor ACE2 and the cellular protease TMPRSS2 for entry into target cells. 2020;

18. Hoffmann M, Kleine-Weber H, Schroeder S, Krüger N, Herrler T, Erichsen S, et al. SARSCoV-2 Cell Entry Depends on ACE2 and TMPRSS2 and Is Blocked by a Clinically Proven Protease Inhibitor. Cell. 2020;181(2):271-280.e8.

19. Lundstrom K, Seyran M, Pizzol D, Adadi P, Elaziz TMA, Hassan SS, et al. Origin of SARSCoV-2. Viruses. 2020;12:10-3.

20. Wrapp D, Wang N, Corbett KS, Goldsmith JA, Hsieh CL, Abiona O, et al. Cryo-EM structure of the 2019-nCoV spike in the prefusion conformation. Science (80- ). 2020 ;367 (6483) :1260 -3.

21. Kirchdoerfer RN, Wang N, Pallesen J, Wrapp D, Turner HL, Cottrell CA, et al. Stabilized coronavirus spikes are resistant to conformational changes induced by receptor recognition or proteolysis. Sci Rep. 2018;8(1):1-11. Available from: http://dx.doi.org/10.1038/s41598-018-34171-7

22. Yan S, Sun H, Bu X, Wan G. New Strategy for COVID-19: An Evolutionary Role for RGD Motif in SARS-CoV-2 and Potential Inhibitors for Virus Infection. Front Pharmacol. 2020;11(June):1-5.

23. Zhang $\mathrm{C}$, Zheng $\mathrm{W}$, Huang $\mathrm{X}$, Bell EW, Zhou $X$, Zhang Y. Protein Structure and Sequence Reanalysis of 2019-nCoV Genome Refutes Snakes as Its Intermediate Host and the Unique Similarity between Its Spike Protein Insertions and HIV-1. J Proteome Res. 2020;19(4):135160.

24. Ji W, Wang W, Zhao X, Zai J, Li X. Crossspecies transmission of the newly identified coronavirus 2019-nCoV. J Med Virol. 2020;92(4):433-40.

25. Zhou $P$, Yang $X$ Lou, Wang XG, Hu B, Zhang $\mathrm{L}$, Zhang $\mathrm{W}$, et al. A pneumonia outbreak associated with a new coronavirus of probable bat origin. Nature. 2020;579(7798):270-3. Available from: http://dx.doi.org/10.1038/s41586-020-2012-7 
26. Wang J, Zhao S, Liu M, Zhao Z, Xu Y, Wang $\mathrm{P}$, et al. ACE2 expression by colonic epithelial cells is associated with viral infection, immunity and energy metabolism. medRxiv. 2020;1-13.

27. Chu DK, Akl EA, Duda S, Solo K, Yaacoub S, Schünemann HJ, et al. Physical distancing, face masks, and eye protection to prevent person-toperson transmission of SARS-CoV-2 and COVID-19: a systematic review and metaanalysis. 2020;1973-87.

28. Bourouiba L. Turbulent gas clouds and respiratory pathogen emissions: potential implications for reducing transmission of COVID-19. JAMA - J Am Med Assoc. 2020 ;323 (18):1837-8.

29. Dyani Lewis. Is the Coronavirus Airborne? Experts can't Agree. Nature. 2020;580.

30. Chen H, Guo J, Wang C, Luo F, Yu X, Zhang $\mathrm{W}$, et al. Clinical characteristics and intrauterine vertical transmission potential of COVID-19 infection in nine pregnant women: a retrospective review of medical records. Lancet. 2020;395(10226):809-15. Available from: http://dx.doi.org/10.1016/S01406736(20)30360-3

31. Simões e Silva AC, Leal CRV. Is SARS-CoV2 Vertically Transmitted? Front Pediatr. 2020;8(May):1-5.

32. van Doremalen $\mathrm{N}$, Bushmaker $\mathrm{T}$, Morris $\mathrm{D}$. Aerosol and surface stability of sars-cov-2 as compared with SARS-CoV-1. N Engl J Med. 2020;0-2.

33. Ben-Shmuel A, Brosh-Nissimov T, Glinert I, Bar-David E, Sittner A, Poni R, et al. Detection and infectivity potential of Severe Acute Respiratory Syndrome Coronavirus 2 (SARSCoV-2) environmental contamination in isolation units and quarantine facilities. Clin Microbiol Infect. 2020;2(12):1658-62.

34. Wang W, Tang J, Wei F. Updated understanding of the outbreak of 2019 novel coronavirus (2019-nCoV) in Wuhan, China. J Med Virol. 2020;92(4):441-7.

35. Docherty AB, Harrison EM, Green CA, Hardwick HE, Pius R, Norman L, et al. Features of 20133 UK patients in hospital with covid-19 using the ISARIC WHO Clinical Characterisation Protocol: Prospective observational cohort study. BMJ. 2020;369(March):1-12.

36. Guan W, Ni Z, Hu Y, Liang W, Ou C, He J, et al. Clinical characteristics of coronavirus disease 2019 in China. N Engl J Med. 2020;382(18):1708-20.

37. Yang X, Yu Y, Xu J, Shu H, Xia J, Liu H, et al. Clinical course and outcomes of critically ill patients with SARS-CoV-2 pneumonia in Wuhan , China: a single-centered, retrospective, observational study. Lancet
Respir. 8(5):475-81. Available from: http://dx.doi.org/10.1016/S22132600(20)30079-5

38. Holban T, Cojocaru S, Iarovoi L. Clinical manifestations and evolutionary peculiarities of COVID-19 infection (review). MJHS. 2020;24(2):70-83.

39. Gold JAW. Race, Ethnicity, and Age Trends in Persons Who Died from COVID-19 - United States, May-August 2020. MMWR. 2020;69.

40. Chan JFW, Yuan S, Kok KH, To KKW, Chu H, Yang J, et al. A familial cluster of pneumonia associated with the 2019 novel coronavirus indicating person-to-person transmission: a study of a family cluster. Lancet [Internet]. 2020;395(10223):514-23. Available from: http: // dx . doi . org /10 .1016 / S0140 -6736 (20) 30154 - 9

41. Zhang $C$, Huang S, Zheng F, Dai Y. Controversial treatments: An updated understanding of the coronavirus disease 2019. J Med Virol. 2020;92(9):1441-8.

42. Wiersinga WJ, Rhodes A, Cheng AC, Peacock SJ, Prescott HC. Pathophysiology, transmission, diagnosis, and treatment of coronavirus disease 2019 (COVID-19): A Review. JAMA - J Am Med Assoc. 2020;323(16):1574-81.

43. Chan PKS, Tang JW, Hui DSC. SARS : clinical presentation, transmission, pathogenesis and treatment options. 2006;(May).

44. Lauer SA, Grantz KH, Bi Q, Jones FK, Zheng Q, Meredith HR, et al. the incubation period of coronavirus disease 2019 ( COVID-19) from publicly reported confirmed cases : estimation and application. Ann Intern Med. 2020;172(9):577-82.

45. Covid-net LCD. Hospitalization rates and characteristics of patients hospitalized with. morb mortal Wkly Rep. 2020;69(15):458-64.

46. Docherty AB, Harrison EM, Green CA, Hardwick HE, Pius R, Norman L, et al. Features of 20133 UK patients in hospital with covid-19 using the ISARIC WHO Clinical Characterisation Protocol: prospective observational cohort study. BMJ. 2020;

47. Grasselli G, Zangrillo A, Zanella A, Antonelli M, Cabrini L, Castelli A, et al. baseline characteristics and outcomes of 1591 patients infected with SARS-CoV-2 admitted to ICUs of the Lombardy Region, Italy. JAMA. 2020; ;323(16):1574-81

48. Reddy G, Public RN, Seattle H, County K, Ali $\mathrm{H}$, Kay M, et al. Alterations in smell or taste in mildly symptomatic outpatients with SARSCoV-2 Infection. JAMA - J Am Med Assoc. 2020;223(20):2089-209.

49. Lechien JR, Estomba CMC, Siati DR De, Horoi M. Olfactory and gustatory dysfunctions as a clinical presentation of mild - to - moderate 
forms of the coronavirus disease (COVID - 19 ): a multicenter European study. Eur Arch OtoRhino-Laryngology. 2020;277(8):2251-61. Available from: https://doi.org/10.1007/s00405-020-05965-1

50. Chen N, Zhou M, Dong X, Qu J, Gong F, Han $\mathrm{Y}$, et al. Epidemiological and clinical characteristics of 99 cases of 2019 novel coronavirus pneumonia in Wuhan, China: a descriptive study. Lancet. 2020;395(10223):507-13. Available from: http://dx.doi.org/10.1016/S01406736(20)30211-7

51. Landman A, Feetham L, Stuckey D. Cancer patients in SARS-CoV-2 infection: a nationwide analysis in China. 2020;2045(20):335-7.

52. Mirlashari J, Ebrahimpour F, Salisu WJ. War on two fronts: Experience of children with cancer and their family during COVID-19 pandemic in Iran. J Pediatr Nurs [Internet]. 2020; Available from: https://doi.org/10.1016/j.pedn.2020.10.024

53. Dakhil ZA, Farhan HA. Cardiovascular impacts of COVID-19 Pandemic: from presentation to management: current and future perspectives. J Clin Exp Invest. 2020;11(3):em00739.

54. Mallapaty S. Mini organs reveal how the coronavirus ravages the body. Nature. 2020 Jun 22;583(7814):15-6.

55. Ai T, Lv W. Correlation of Chest CT and RTPCR Testing for Coronavirus Disease 2019 ( COVID-19 ) in China : A Report of 1014 Cases. Radiology. 2020;

56. Wang W, Xu Y, Gao R, Lu R, Han K, Wu G, et al. Detection of SARS-CoV-2 in Different Types of Clinical Specimens. JAMA - J Am Med Assoc. 2020;323(18):1843-4.

57. Williams E, Bond $\mathrm{K}$, Zhang B, Putland M, Williamson DA. Saliva as a noninvasive specimen for detection of sars-cov-2. J Clin Microbiol. 2020;58(8):1-2.

58. Wong KT, Antonio GE, Hui DSC, Lee N, Yuen EHY, Wu A, et al. Severe acute respiratory syndrome: Radiographic appearances and pattern of progression in 138 patients. Radiology. 2003;228(2):401-6.

59. Sethuraman N, Jeremiah SS, Ryo A. Interpreting Diagnostic Tests for SARS-CoV-2. JAMA - J Am Med Assoc. 2020;323(22):224951.

60. Guo L, Ren L, Yang S, Xiao M, Chang D, Yang $\mathrm{F}$, et al. Profiling early humoral response to diagnose novel coronavirus disease (COVID19). Clin Infect Dis. 2020;71(15):778-85.

61. Zhang F, Abudayyeh OO, Gootenberg JS, Sciences C, Mathers L. A protocol for detection of COVID-19 using CRISPR diagnostics. Bioarchive. 2020;1-8.
62. Di L, Fu Y, Sun Y, Li J, Liu L, Yao J, et al. RNA sequencing by direct tagmentation of RNA/DNA hybrids. Proc Natl Acad Sci U S A. 2020;117(6):2886-93.

63. Lo MK, Feldmann F, Gary JM, Jordan R, Bannister R, Cronin J, et al. Remdesivir (GS5734) protects African green monkeys from Nipah virus challenge. Sci Transl Med. 2019;11(494):1-12.

64. Sheahan TP, Sims AC, Graham RL, Menachery VD, Lisa E, Case JB, et al. Broad-spectrum antiviral GS-5734 inhibits. Sci Transl Med. 2017;9(396).

65. Holshue ML, DeBolt C, Lindquist $\mathrm{S}$, Lofy KH, Wiesman J, Bruce H, et al. First case of 2019 novel coronavirus in the United States. N Engl J Med. 2020;382(10):929-36.

66. Wang M, Cao R, Zhang L, Yang X, Liu J, Xu $\mathrm{M}$, et al. Remdesivir and chloroquine effectively inhibit the recently emerged novel coronavirus (2019-nCoV) in vitro. Cell Res. 2020;30(3):269-71.

67. Devaux CA, Rolain JM, Colson P, Raoult D. New insights on the antiviral effects of chloroquine against coronavirus: what to expect for COVID-19? Int J Antimicrob Agents. 2020;55(5).

68. Zhou D, Dai SM, Tong Q. COVID-19: A recommendation to examine the effect of hydroxychloroquine in preventing infection and progression. J Antimicrob Chemother. 2020;75(7):1667-70.

69. Rosenberg ES, Dufort EM, Udo T, Wilberschied LA, Kumar J, Tesoriero J, et al. Association of treatment with hydroxychloroquine or azithromycin with inhospital mortality in patients with COVID-19 in New York State. JAMA - J Am Med Assoc. 2020;323(24):2493-502.

70. Geleris J, Sun Y, Platt J, Zucker J, Baldwin M, Hripcsak G, et al. Observational study of hydroxychloroquine in hospitalized patients with COVID-19. N Engl J Med. 2020;382(25):2411-8.

71. Andre C. Kalil. Treating COVID-19-OffLabel drug use, compassionate use, and randomized clinical trials during pandemics. JAMA. 2020 May 19;323(19):1897-8.

72. Mahévas M, Tran VT, Roumier M, Chabrol A, Paule R, Guillaud C, et al. Clinical efficacy of hydroxychloroquine in patients with covid-19 pneumonia who require oxygen: Observational comparative study using routine care data. BMJ. 2020;369:1-9.

73. Osadchy A, Ratnapalan T, Koren G. Ocular toxicity in children exposed in utero to antimalarial drugs: Review of the literature. J Rheumatol. 2011;38(12):2504-8. 
74. Croxtall JD, Perry CM. Lopinavir Ritonavir: A review of its use in the management of HIV-1 infection. Drugs. 2010;70(14):1885-915.

75. Cao B, Wang Y, Wen D, Liu W, Wang J, Fan $\mathrm{G}$, et al. A trial of lopinavir-ritonavir in adults hospitalized with severe covid-19. N Engl J Med. 2020;382(19):1787-99.

76. Khalili JS, Zhu H, Mak NSA, Yan Y, Zhu Y. Novel coronavirus treatment with ribavirin: Groundwork for an evaluation concerning COVID-19. J Med Virol. 2020;92(7):740-6.

77. Foolad F, Aitken SL, Shigle TL, Prayag A, Ghantoji S, Ariza-Heredia E, et al. Oral versus aerosolized ribavirin for the treatment of respiratory syncytial virus infections in hematopoietic cell transplant recipients. Clin Infect Dis. 2019;68(10):1641-9.

78. Stockman LJ, Bellamy R, Garner P. SARS: Systematic review of treatment effects. PLoS Med. 2006;3(9):1525-31.

79. Altinbas S, Holmes JA, Altinbas A. Hepatitis C Virus Infection in Pregnancy: An Update. Gastroenterol Nurs. 2020;43(1):12-21.

80. Mustafa S, Balkhy H, Gabere MN. Current treatment options and the role of peptides as potential therapeutic components for Middle East Respiratory Syndrome (MERS): A review. J Infect Public Health [Internet]. 2018;11(1):917. Available from: https://doi.org/10.1016/j.jiph.2017.08.009

81. Rizk JG, Kalantar-Zadeh K, Mehra MR, Lavie CJ, Rizk Y, Forthal DN. PharmacoImmunomodulatory Therapy in COVID-19. Drugs [Internet]. 2020;80(13):1267-92. Available from: https://doi.org/10.1007/s40265-020-01367-z

82. Montón C, Ewig S, Torres A, El-Ebiary M, Filella X, Rañó A, et al. Role of glucocorticoids on inflammatory response in nonimmunosuppressed patients with pneumonia: A pilot study. Eur Respir J. 1999;14(1):218-20.

83. Hylands $M$, Moller MH, Asfar $\mathrm{P}$, Toma A, Frenette AJ, Beaudoin N, et al. A systematic review of vasopressor blood pressure targets in critically ill adults with hypotension. Can J Anesth. 2017;64(7):703-15.

84. Franchimont D, Kino T, Galon J, Meduri GU, Chrousos G. Glucocorticoids and inflammation revisited: The state of the art - NIH Clinical Staff Conference. Neuroimmunomodulation. 2002;10(5):247-60.

85. Russell CD, Millar JE, Baillie JK. Clinical evidence does not support corticosteroid treatment for 2019-nCoV lung injury. Lancet. 2020;395(10223):473-5.

86. Horby P, Lim W, Emberson J, Mafham M, Bell $\mathrm{J}$, Linsell L, et al. Effect of dexamethasone in hospitalized patients with COVID-19 Preliminary Report. medRxiv. 2020;
87. Outcomes M. Risk Factors associated with acute respiratory distress syndrome and death in patients with coronavirus disease 2019 pneumonia in Wuhan, China. 2020;180(7):93443.

88. Chen L, Xiong J, Bao L, Shi Y. Convalescent plasma as a potential therapy for COVID-19. Lancet Infect Dis [Internet]. 2020;20(4):398400. Available from: http: // dx. doi. Org /10. 1016 /S1473-3099(20)30141-9

89. Casadevall A, Pirofski L, Casadevall A, Pirofski L. The convalescent sera option for containing COVID-19. J Clin Invest. 2020;130(4):1545-8.

90. Soo YOY, Cheng Y, Wong R, Hui DS, Lee CK, Tsang KKS, et al. Retrospective comparison of convalescent plasma with continuing high-dose methylprednisolone treatment in SARS patients. Clin Micro- biol Infect. 2004;10(7):676-8.

91. Arabi Y, Balkhy H, Hajeer AH, Bouchama A, Hayden FG, Omari A Al, et al. effects of convalescent plasma therapy for patients with Middle East respiratory syndrome coronavirus infection : a study protocol. Springerplus. 2015;

92. Shen C, Wang Z, Zhao F, Yang Y, Li J, Yuan J, et al. Treatment of 5 Critically Ill Patients With COVID-19 With Convalescent Plasma. JAMA. 2020;323(16):1582-9.

93. Li L, Zhang W, Hu Y, Tong X, Zheng S, Yang $J$, et al. Effect of convalescent plasma therapy on time to clinical improvement in patients with severe and life-threatening COVID-19 A Randomized Clinical Trial. 2020;

94. Jüni $P$, Rothenbühler $M$, Bobos $P$, Thorpe KE, Da Costa BR, Fisman DN, et al. Impact of climate and public health interventions on the COVID-19 pandemic: A prospective cohort study. Cmaj. 2020;192(21):E566-73.

95. Pan A, Liu L, Wang C, Guo H, Hao X, Wang $\mathrm{Q}$, et al. Association of public health interventions with the epidemiology of the COVID-19 Outbreak in Wuhan, China. JAMA - J Am Med Assoc. 2020;323(19):1915-23.

96. Flaxman S, Mishra S, Gandy A, Unwin HJT, Mellan TA, Coupland H, et al. Estimating the effects of non-pharmaceutical interventions on COVID-19 in Europe. Nature. 2020;584(7820):257-61.

97. Xiao Y, Tang B, Wu J, Cheke RA, Tang S. Linking key intervention timing to rapid decline of the COVID-19 effective reproductive number to quantify lessons from mainland China. Int J Infect Dis. 2020;97:296-8. Available from: https://doi.org/10.1016/j.ijid.2020.06.030

98. Wei X, Wang Z, Liao X, Guo W, Wen J, Qin T, et al. Efficacy of vitamin $\mathrm{C}$ in patients with sepsis: An updated meta-analysis. Eur J Pharmacol J. 2020;868. 
99. Fisher BJ, Seropian IM, Kraskauskas D, Thakkar JN, Voelkel NF, Fowler AA, et al. Ascorbic acid attenuates lipopolysaccharideinduced acute lung injury. Crit Care Med. 2011;39(6):1454-1460.

100.H H. Vitamin C intake and susceptibility to pneumonia. Pediatr Infect Dis J. 1997;16:8367.

101. Nonnecke BJ, Mcgill JL, Ridpath JF, Sacco RE, Lippolis JD, Reinhardt TA. Acute phase response elicited by experimental bovine diarrhea virus ( BVDV) infection is associated with decreased vitamin $D$ and $E$ status of vitamin-replete preruminant calves. J Dairy Sci
[Internet]. 2014;97(9):5566-79. Available from: http://dx.doi.org/10.3168/jds.2014-8293

102.Le TT, Andreadakis Z, Kumar A, Román RG, Tollefsen S, Saville M, et al. The COVID-19 vaccine development landscape. Nat Rev Drug Discov [Internet]. 2020;19(May):305-6. Available from: http: // dx. doi. Org /10. 1038 /d41573-020-00073-5

103.Lurie N, Saville M, Hatchett R, Halton J. Developing Covid-19 vaccines at pandemic Speed. N Engl J Med. 2020;1969-73.

104. Harman S, Herten-Crabb A, Morgan R, Smith J, Wenham C. COVID-19 vaccines and women's security. The Lancet. 2020.

Baghdad Iraqi Journal Pharmaceutical Sciences by bijps is licensed under a Creative Commons Attribution

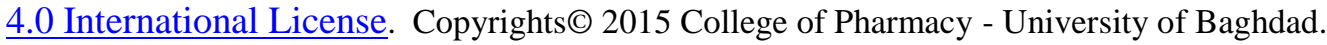

